\title{
LA AUTORIDAD DEL DERECHO Y LA TEORÍA \\ DE UN DERECHO CON AUTORIDAD. RÉPLICA A MIS COMENTARISTAS *
}

Carlos F. Rosenkrantz

I

"La Autoridad del Derecho y la Injusticia Económica y Social" (en adelante "LAD") es un artículo que desarrolla cuatro puntos principales de algún modo independientes unos de otros. Primero, una hipótesis acerca de las razones por las que las teorías tradicionales de la autoridad del derecho no han obtenido el consenso necesario para convertirse en respuestas canónicas a la cuestión de qué es lo que explica y justifica la obligación de obedecer el derecho. Segundo, la sugerencia de que si queremos explicar la obligación de obedecer el derecho debemos hacer extensas referencias a la especial relación que existe entre aquellos que se encuentran obligados por el derecho y la comunidad a la que ellos pertenecen o de la que son miembros. Tercero, una tesis acerca de las características que debe satisfacer la relación entre la comunidad y sus miembros para que sea sensato sostener que ella es una relación de membresía a una comunidad. Por último, la conclusión de que si somos miembros de una comunidad tenemos la obligación (no última sino pro tanto) de obedecer el derecho de dicha comunidad, incluso en circunstancias de injusticia distributiva, esto es, incluso cuando los recursos

\footnotetext{
* Agradezco los comentarios de Paula Gaido, Paolo Comanducci, Andrés Rossler y a los participantes del Seminario Internacional de Bahía Blanca 2006.
} 
económicos y políticos están mal o injustamente distribuidos entre los miembros de dicha comunidad.

No obstante que todos mis comentaristas (con excepción de Rodríguez a quien me referiré en la última sección de esta réplica) comparten algunos de estos cuatro puntos, todos están lejos de creer que LAD haya dado respuestas definitivas a los problemas que yo trato. Los argumentos en los que basan su escepticismo son muchos y de muy distinto tenor por lo que me ha parecido mejor responderles de un modo más bien global. Por lo tanto, en lugar de tratar punto por punto cada uno de los argumentos de cada uno de mis comentaristas me concentraré en los grandes problemas que ellos introducen. En primer lugar, me referiré a la naturaleza de mis ideas. En segundo lugar, al requisito de la "generalidad". En el contexto de esta discusión haré algunas referencias a la teoría general del derecho y a la mejor manera de concebirlo. Luego analizaré las críticas de Seleme e Iglesias, quienes sostienen que mi test de membresía es demasiado fácil de satisfacer y que, como consecuencia de ello, veo obligaciones legales donde no debería haberlas. En las secciones IV y V de esta réplica argumentaré que mi concepción de la membresía es preferible a la de Seleme e Iglesias no solo a la luz del valor del "cambio sistémico" sino también en virtud de consideraciones de justicia. Finalmente, cerraré esta réplica con algunos comentarios sobre Rodríguez y las razones por las que debemos resistir su afirmación de que "el derecho (no puede imponer) genuinos deberes en contextos de manifiesta desigualdad económica".

II

En su contribución, Grosman sugiere que yo incurro en algún tipo de inconsistencia o que someto a los lectores a algún tipo de trampa o traición pues yo, "a pesar del tono explicativo de (mi) análisis...., (yo ofrezco) una teoría justificatoria" del derecho y de su fuerza vinculante.

Los comentarios de Grosman parten de la extendida idea de que existe una diferencia entre el mundo de la explicación y el mundo de la justificación 
y que, por lo tanto, no se puede pasar de uno a otro sin incurrir en un salto lógico o en alguna falacia. Pero el punto de partida de Grosman es equivocado. Imagínese usted que alguien le preguntara acerca de la amistad en nuestra cultura. Usted seguramente responderá esta pregunta indicando a su interlocutor que hay amistad si, entre otras cosas, existe una actitud o disposición a hacer cosas el uno por el otro, no por razones estratégicas ni para obtener algo del otro en el futuro sino en virtud de que uno y otro valoran la existencia en ambos de esa actitud o disposición. Con esta respuesta, sin duda, usted habrá "explicado" a su interlocutor algo acerca de la amistad que, como tal, puede ser verdadero o falso. Pero al explicar usted también habrá sugerido qué es lo que debe hacer su interlocutor si llegara a estar involucrado como amigo con alguien en nuestra cultura. En otras palabras, a pesar de que intentó "explicar" la amistad lo que usted hizo -su intento de explicación- no tiene solo importancia explicativa. Dado que la amistad es una práctica normativa, esto es, es una práctica que se realiza con conciencia de que ella instancia algún valor, su explicación necesariamente conlleva una propuesta acerca de lo que en ciertas circunstancias debe hacerse. Por lo tanto, su explicación es también una justificación. Con el derecho pasa lo mismo. Como el derecho es también una práctica o un fenómeno normativo, toda explicación implica una justificación. Por ello, yo no incurro en salto lógico o falacia alguna si digo que lo que quiero hacer es "explicar" la autoridad del derecho qua derecho y afirmo, al mismo tiempo, que esta explicación nos indicará por qué debemos obedecer el derecho (o más limitadamente, por qué todos tenemos razones para obedecerlo aun cuando dichas razones no sean absolutas).

Usted podría problematizar mi respuesta a Grosman. Podría sostener que es posible explicar/justificar en los casos en los que uno explica/justifica una práctica o un fenómeno normativo pero que el derecho no es ese tipo de práctica o fenómeno. Esta es una crítica básica que no puedo responder de un modo completo y convincente. No obstante ello, no puedo dejar pasar la oportunidad de señalar dos cosas importantes: primero, el hecho de que el 
derecho sirva un valor -el valor del cambio sistémico, esto es, la posibilidad de que se constituya una comunidad entre aquellos sujetos a la misma autoridad y que ella cambie como tal- es una razón de peso que sustenta la visión del derecho como una práctica o fenómeno normativo ${ }^{1}$. El cambio sistémico es el "punto" de la práctica o fenómeno que es el derecho y la fuente de su normatividad ${ }^{2}$. En segundo lugar, es posible "confirmar" la normatividad del derecho mirando a lo que de hecho sucede en el mundo. En efecto, la idea de que el derecho es una práctica o fenómeno normativo se sustenta no solo por la pretensión del derecho ${ }^{3}$ de obligar sino, además, por la creencia de la mayoría de la gente (salvo los filósofos políticos entre los que se cuentan mis comentaristas) de que el derecho de hecho obliga ${ }^{4}$.

III

En LAD afirmé que uno de los requisitos formales que debe satisfacer toda teoría de la autoridad del derecho es el requisito de "generalidad". Una teoría de la autoridad del derecho debe permitirnos entender por qué el derecho obliga a todos, y no solo a aquellos caracterizados por ciertos rasgos particulares

\footnotetext{
${ }^{1}$ En mi visión la relación entre el cambio sistémico y el derecho no es “externa', como lo es la relación entre el derecho y la justicia. El cambio sistémico es un valor inmanente al derecho. No es instrumental a la realización de ningún otro valor y vale únicamente para aquellos que por ser miembros de la comunidad política están vinculados por el derecho.

${ }^{2}$ La idea de que el derecho tiene un "punto" no es universalmente aceptada. Hart, por ejemplo, pensaba que el derecho no estaba asociado con ningún valor. Ver Hart, H.L The Concept of Law, Postcript.

${ }^{3}$ El hecho de que el derecho pretende obligar es una característica del derecho. En este sentido Raz ha dicho que es una verdad conceptual que el derecho reclama autoridad para sí. Ver, Raz, Joseph “Authority, Law and Morality” en Ethics in the Public Domain, Oxford; Clarendon Press, 1994, pag. 215.

${ }^{4}$ El derecho de hecho obliga en el sentido de que todos nos sentimos obligados por el derecho de un modo diferente, a pesar de Austin, al modo en que nos sentimos obligados frente al delincuente que nos fuerza a elegir la bolsa o la vida.
} 
como, por ejemplo, ser un funcionario, haber jurado obediencia, haberse beneficiado por el derecho, etc.

Marisa Iglesias no está convencida de que el requisito de "generalidad", tal como yo lo entiendo, sea plausible. Según Iglesias, mi concepción de la generalidad es demasiado exigente pues, de acuerdo con sus términos, una teoría de la autoridad del derecho sólo sería general si mostrase que todos los destinatarios de las normas jurídicas tienen el deber de obediencia lo que, según Iglesias, es imposible.

Desde el otro flanco, Grosman, Seleme y Rodríguez creen que mi concepción de la autoridad del derecho es insuficientemente general y, por lo tanto, que no es mejor que todas aquellas teorías tradicionales que critico. Seleme afirma que mi teoría, en realidad, no explica por qué todos deben obedecer el derecho y, por lo tanto, no puede afirmarse que ella sea general. Ello es así, según Seleme, porque el conjunto de aquellos a quienes el derecho se dirige -conjunto al que Seleme llama la "comunidad jurídica"- es siempre más abarcativo que el conjunto de los miembros de la comunidad política, los únicos que según mi visión están obligados por el derecho.

Los comentarios anteriores me brindan una buena oportunidad para aclarar lo que exige el requisito de generalidad y para precisar algunas ideas que no estaban suficientemente claras en LAD. Empecemos con Iglesias. En un punto Iglesias tiene razón. El requisito de la generalidad de una teoría sería demasiado fuerte si nos exigiese mostrar que todos los destinatarios de las normas -todos aquellos a quienes se dirigen las normas- están obligados por el derecho. Pero el requisito de generalidad que yo tengo en mente no exige esto. En mi concepción la generalidad se satisface con algo más modesto, más precisamente, con una explicación de la obligación de obedecer el derecho por parte de aquellos a quienes el derecho obliga de un modo especial por el hecho de ser partes de la comunidad política que se expresa mediante dicho derecho o que se identifica con él (los "súbditos" del derechos),

\footnotetext{
${ }^{5}$ En justicia a Iglesias debo reconocer que el lenguaje que usé en LAD es un poco ambiguo pues en varios pasajes me refiero a los "destinatarios" del derecho.
} 
independientemente de cuántos sean aquellos a quienes el derecho se dirige o quiénes sean sus destinatarios.

Esta aclaración sirve también para responder a Seleme. Es verdad que la "comunidad jurídica", entendida como el conjunto de individuos a quienes el derecho se dirige, no coincide con la "comunidad política", entendida como el conjunto de individuos a quienes el derecho obliga ya que, como sugiere Seleme, aquella comunidad es más inclusiva que esta. Pero la falta de coincidencia entre estos dos tipos de comunidades no representa un problema, ni muestra que mi teoría sea insuficientemente general. La generalidad de una teoría de la autoridad jurídica se satisface plenamente cuando ella explica por qué todos los obligados por el derecho deben obedecerlo. En virtud de ello, no puede pensarse que una teoría que no da cuenta de la obligación de obedecer el derecho de aquellos que no son miembros de la comunidad política sea insuficientemente general si es que, como yo sostengo, quienes no son miembros de la comunidad política no tienen la obligación de obedecer el derecho, por más que sean los destinatarios de sus normas.

Para enfatizar lo que digo en el párrafo precedente volvamos a Grosman. Grosman nos invita a pensar el caso en que usted "fuera secuestrado y luego trasladado subrepticiamente a un país vecino y allí liberado". Todos diríamos, dice Grosman, que usted "no debe(ría) mantenerse al margen de las exigencias de las normas del país" de su liberación. Este ejemplo muestra, según Grosman, que estamos obligados por el derecho de comunidades políticas de las que no somos miembros lo que, a su vez, demuestra que mi teoría de la autoridad jurídica es insuficientemente general pues ella no puede explicar algunos casos de obligación jurídica, más precisamente, el caso de la obligación de obedecer el derecho por parte de quienes no son miembros de la comunidad política.

Ahora imagine que el derecho del país de su liberación establece que usted debe pagar impuestos, incluso por las ganancias que obtuvo con anterioridad en su país de origen y, también, que debe servir en el ejército por un par de años. Si Grosman tuviera razón, esto es, si el derecho del país de su liberación tuviera autoridad sobre usted y lo obligara qua derecho, 
usted debería hacer ambas cosas: pagar impuestos y alistarse en el ejército. Pero todos coincidiríamos en que esto es demasiado pedir y la única razón que puede explicar esta reacción es que, a pesar de lo que sugiere Grosman, usted no está obligado por el derecho del país de su liberación. Esta conclusión, que refuerza mi teoría de la autoridad jurídica (y contradice la que Grosman presupone al criticarme) muestra que el ejemplo de Grosman no prueba lo que necesita probar pues el que usted "no deb(a) mantenerse al margen de las exigencias de las normas del país de su liberación" no implica en modo alguno que usted deba obedecer estas normas qua derecho (sino, solamente, que usted debe mostrar alguna deferencia por el país en el que fue liberado) y si no prueba que usted no debe obedecer estas normas qua derecho, no puede pretender haber encontrado un caso de obligación jurídica que no pueda ser explicado por mi teoría de la autoridad ${ }^{6}$.

Lo anterior, creo, es suficiente defensa de la "generalidad" de mi teoría de la autoridad jurídica. Lo que he dicho hasta aquí neutraliza las críticas de

${ }^{6}$ En uno de los pasajes de su contribución Grosman sugiere que la obligación de obedecer el derecho no puede estar asociada con la membresía en razón de que en muchos casos quien no es un miembro de la comunidad debe obedecer sus normas. Grosman ejemplifica y dice que todos teníamos la obligación de obedecer las normas del Código Civil relativas a los contratos o a la responsabilidad civil durante la dictadura argentina de los años 1976 y 1983, aún cuando de acuerdo con mis criterios, en virtud de que no podíamos participar en el proceso de toma de decisiones colectivas, no éramos miembros de ninguna comunidad política. Grosman incurre en un error. Tal como lo sostengo en el texto el hecho de que debamos obedecer ciertas normas no implica que las debamos obedecer qua derecho ni que dichas normas tengan autoridad jurídica sobre nosotros. Así, usted debe acatar la regulación de los contratos del Código Civil no porque dicha regulación es el derecho sino porque el hecho de haber contratado en el contexto en el cual todos vemos al Código Civil como la fuente de regulación de nuestras obligaciones recíprocas, implica una invitación a aquel con quien usted contrató a que genere la expectativa de que usted honrará sus obligaciones en los términos del Código Civil y es esta invitación lo que lo obliga moralmente a hacer lo que el Código Civil dice que usted debe hacer. Del mismo modo, usted debe acatar la regulación de la responsabilidad extracontractual no porque ella es legalmente obligatoria sino porque ella es una manera en la que usted da cuenta de las obligaciones que usted tiene a la luz de la justicia correctiva. 
mis comentaristas. Pero, no obstante ello, quiero aprovechar la oportunidad para terminar de convencer a Grosman y a Seleme de que sólo los miembros de la comunidad política están sujetos a la autoridad del derecho.

La afirmación de que el derecho obliga sólo a los miembros de la comunidad política depende, por supuesto, de qué es el derecho. Esto es de qué es lo que afirmamos cuando, por ejemplo, decimos "el derecho de la Argentina no permite cortar las rutas" o "en la Argentina el derecho a la libertad de expresión está garantizado" o "la moral y el derecho no son la misma cosa". Si, como creían los prescriptivistas con Austin a la cabeza, el derecho fuera un fenómeno de poder cualitativamente similar a las órdenes respaldadas por amenazas, quienes no son miembros de la comunidad política estarían igual "obligados" por el derecho si órdenes respaldadas por amenazas se dirigieran a ellos. Lo mismo sucedería si el derecho fuera meramente un orden normativo reconocido o aceptado como tal por los órganos encargados de resolver los conflictos sociales que tienen a su disposición el monopolio de la coerción, como pensaban los hartianos. En este caso, la obligación de alguien de obedecer el derecho no estará supeditada a su pertenencia a una particular comunidad sino a que las normas que le imponen las pretendidas obligaciones legales sean aceptadas en la práctica por quienes tienen la responsabilidad de hacer aplicar dichas normas sobre los demás?.

En virtud de que, entonces, mi empresa depende de qué entendemos por derecho debo incursionar en el ámbito de la teoría jurídica, algo que no hice en LAD y por lo que fui criticado por mis comentaristas. Mi objetivo no es presentar una teoría del derecho hecha y derecha sino, mucho más modestamente, mostrar que es plausible pensar que la membresía puede

\footnotetext{
${ }^{7}$ La necesidad de sustentar mi concepción de la autoridad jurídica en una teoría del derecho ha sido bien advertida por mis comentaristas, en especial, por Grosman. Grosman dice, por ejemplo, que yo "para evitar las contradicciones con el requisito de la generalidad 'requier(o) una concepción del derecho en virtud de la cual el principio de membresía no sea algo que algunos derechos satisfacen y otros no, sino un elemento constitutivo de todo derecho"'.
} 
ser una de las propiedades que debe satisfacer un sistema normativo para alcanzar el estatus de "derecho" para alguien en particular o, para ponerlo en las palabras de Grosman, mostrar que la "membresía debe ser parte del concepto de derecho...o que el derecho no (será) derecho si no cumple el principio de membresía".

¿Cuándo estamos frente a una teoría del derecho adecuada? Una buena teoría de algo debe dar cuenta de aquello acerca de lo que es una teoría. Así, por ejemplo, las teorías de la física o las teorías del color. Lo mismo sucede en el caso del derecho. El tema es que aquí la cuestión presenta una complejidad adicional en virtud de que no hay algo como el "derecho" que exista per se y que se pueda identificar sin recurrir a una teoría. El derecho es un concepto "teórico" en el sentido de que si bien tiene algunos rasgos que lo caracterizan mas allá de toda duda -paradigmáticamente, la coactividad y su carácter institucional- la determinación de sus contornos definitivos -incluso de algunas de sus características esenciales- dependerá de la teoría que de él tengamos.

Lo anterior es casi verdad aceptada. No hay ya "esencialistas" dispuestos a sostener que es posible identificar el derecho como si fuera algo que está allí afuera con absoluta independencia de todo lo que nosotros pensamos acerca de él. No obstante ello, los desacuerdos acerca de qué es el derecho persisten porque tenemos diferencias acerca de cuál es la función de una teoría del derecho. Así, para muchos una teoría del derecho debe servir primero y principal objetivos epistemológicos, esto es, nos debe servir para conocer mejor los contornos de nuestras prácticas sociales. Raz quizás sea el exponente más destacado de esta visión ${ }^{9}$. Raz cree que la teoría del derecho

8 "Derecho" es "an essentially contested concept". Esta categoría fue sugerida por W. B. Gallie para describir los conceptos que envuelven disputas alrededor de su uso apropiado. Ver Gallie, W. B. Essentially contested concepts in philosophy and the historical understanding. London: Chatto and Windus, 1964: ch viii.

${ }^{9}$ Hart también era partidario de esta visión. Así, en el Postcript dijo que su objetivo era "to give an explanatory and clarifying acocunt of law as a complex social and political institution with a rule-governed (an in this sense "normative") aspect". Ver Hart H.L., The Concept of Law, Postcript, (1994) pag. 239. 
es una incursión en la naturaleza del derecho que toma la forma de una explicación del concepto del derecho y que, por ello, "debe satisfacer una serie de condiciones... una de las cuales es el conocimiento de todos los rasgos esenciales de la cosa respecto de la cual es un concepto" ${ }^{\prime \prime}$. Yo disiento. Creo que el propósito central de una teoría del derecho debe ser práctico. Una teoría del derecho debe ser, como sostiene Soper, una "inquisición acerca de cómo y por qué puede decirse que las reglas aceptadas y respaldadas por los funcionarios son reglas de obligación" "11. La teoría del derecho es parte de la filosofía práctica y, por ello, su función no puede consistir sólo en ayudarnos a identificar los contornos de nuestras prácticas sino que debe servirnos para determinar cuáles de estas prácticas y por qué deben ser vinculantes para nosotros en tanto miembros de una comunidad política ${ }^{12}$.

Si aceptamos que la función central de una teoría del derecho es práctica, es relativamente sencillo dar el primer puntapié en la construcción de una teoría del derecho que incluya la membresía como uno de los elementos de lo que entendemos por derecho. Ni el prescriptivismo de Austin ni el positivismo de Hart, para señalar las dos concepciones que referí precedentemente, pueden ser correctas. Las teorías de Austin y de Hart no conectan la respuesta a la pregunta acerca de qué es el derecho con la respuesta a la pregunta acerca de lo que debemos hacer. Para Austin el derecho es un

\footnotetext{
${ }^{10}$ Es curioso que un proyecto como el de Raz haya ganado tantos adeptos en tanto pareciera que la cuestión de qué es el derecho es importante para nosotros sólo porque ello determinará cómo debe operar el estado y sus instituciones y cuáles son los principios en vigor y cuáles no. Ver Murphy, Liam, Morality and the Concept of Law, manuscrito inédito, pag. 28

${ }^{11}$ Ver Soper, Philip, Una Teoría del Derecho, Centro de Estudios Constitucionales, Madrid 1993, Traducción Ricardo Caracciolo, pag. 28.

${ }^{12}$ Otra manera de expresar el desacuerdo en filosofía jurídica es distinguir entre aquellos que creen que la filosofía jurídica es descriptiva y aquellos que creen que es normativa. Yo creo que es ambas cosas a la vez en virtud de que, como sostuve al defender la naturaleza explicativa de LAD, el derecho es una práctica normativa de modo que su descripción siempre implica la suscripción de un punto de vista acerca de lo que debe hacerse.
} 
fenómeno de fuerza caracterizado únicamente por su escala y, obviamente, así concebido el derecho no puede decirnos nada acerca de nuestras obligaciones personales o institucionales. Hart no es muy distinto en este punto. Si bien Hart reconoce que el derecho "connota" la idea de obligación -y esta es su crítica central a Austin- Hart no cree que el derecho "implique" una obligación por lo que, obviamente, su respuesta a la pregunta acerca de qué es el derecho no puede tener impacto alguno en la respuesta a la pregunta acerca de si debemos o no debemos obedecerlo.

Distinto es con una teoría del derecho que conciba la cuestión de qué es el derecho como esencialmente relacional poniendo énfasis no solo en los rasgos absolutos que se precisan para que un sistema normativo pueda contar como derecho -nuevamente su institucionalidad, su carácter coactivo y, quizás, su carácter general- sino también en la membresía a una comunidad política en virtud de ser éste el rasgo que determina que dicho sistema normativo sea vinculante para alguien en particular y no lo sea, por ejemplo, para otros. Una teoría que hace de la membresía uno de los rasgos constitutivos del derecho en virtud de que entiende que la pregunta "qué es el derecho" debe ser siempre interpretada como la pregunta relacional "cuándo algo es derecho para alguien en particular", es una teoría que puede, a diferencia de las teorías de Austin y Hart, servir fines prácticos en tanto nos puede proveer una concepción del derecho útil para saber cuándo cada uno de nosotros está obligado a hacer lo que el orden coactivo e institucionalizado espera que hagamos.

¿Es esta reconstrucción de lo que el derecho es, que ve al derecho como aquel orden coactivo e institucionalizado que obliga a quienes son miembros de la comunidad política, compatible con nuestras prácticas lingüísticas? Yo diría que sí pero en el caso de que la respuesta correcta fuera no, nada muy importante habría sucedido pues nada muy importante normativamente hablando es regulado por nuestras prácticas lingüísticas. ¿Es viciosamente circular (o viciosamente normativa)? Yo diría que no es más circular (o normativa) que cualquier otra reconstrucción del concepto de derecho que sea algo más que una investigación lingüística. ¿Es correcta? Yo 
diría que sí, no porque esta teoría del derecho dé cuenta acabadamente de ciertas "prácticas sociales concretas" como exige Grosman en su contribución (Dworkin se ha encargado de demostrar que todas las prácticas normativas son "interpretativas" -no concretas- en tanto requieren un ejercicio normativo de determinación de cuáles son sus aspectos más relevantes) ni porque explique mejor que otras el concepto de derecho (no creo que haya un concepto de derecho esperando ser explicado) sino porque al ser relacional, vinculando el orden coactivo e institucionalizado con aquellos a quienes obliga, nos permite saber qué debemos hacer y, de ese modo, satisface mejor que otras teorías el carácter práctico de la respuesta que se espera obtener cuando nos preguntamos qué es el derecho.

Si estoy en lo cierto con lo anterior, si es plausible sostener que la membresía a una comunidad política es uno de los rasgos constitutivos del derecho, la afirmación de que el derecho vincula sólo a los miembros de la comunidad política y que sólo los miembros de la comunidad política están obligados por su derecho decanta con naturalidad. El derecho no puede vincular a quienes no son miembros de la comunidad política no sólo porque no son miembros sino porque lo que pretende vincularlos no es derecho en tanto el derecho es un sistema normativo coactivo e institucionalizado que obliga a quienes son miembros de la comunidad política fuente de dicho derecho ${ }^{13}$.

\footnotetext{
${ }^{13}$ Esta idea de que el concepto de derecho es relacional a ciertos individuos está de alguna forma emparentada con la visión de Fuller para quien el derecho debía entenderse no como un sistema que condensaba las órdenes de soberanos sino como un sistema diseñado para servir los intereses de aquellos sometidos a él (visión de algún modo similar a la de Soper), y con la visión de Waldron para quien la idea de "promulgación" no es la idea central para entender el ideal del "rule of law" sino la idea de que el derecho sea representable como sustentado por toda la comunidad y dirigido a resolver cuestiones de interés de toda la sociedad. Ver Dyzenhaus, The Legitimacy of the Rule of Law, manuscrito inédito.
} 
Dos de mis comentaristas son "asociativistas". Tanto Seleme como Iglesias creen que debemos obedecer el derecho qua derecho por el hecho de ser miembros de la comunidad política que acepta o se expresa mediante dicho derecho. En este punto muy importante ambos están de acuerdo conmigo $^{14}$ apartándose de la ortodoxia en la materia. No obstante ello, ni Seleme ni Iglesias suscriben mi afirmación de que la obligación de obedecer el derecho no se desvanece en circunstancias de injusticia distributiva como

${ }^{14}$ Rodríguez no es asociativista. El no cree que la relación que me une con una comunidad pueda servir para sustentar la obligación de obedecer el derecho de dicha comunidad. Para Rodríguez la "membresía a una misma comunidad política no constituye un hecho normativamente relevante que permita justificar la autoridad del derecho". Más aun, Rodríguez descree de las explicaciones asociativas en general. Así, sostiene que el hecho de ser padre no puede ser una condición suficiente de la autoridad paterna "dado que una multiplicidad de circunstancias quizás no ordinarias sino excepcionales", dice Rodríguez, "pueden determinar que $x$ no tenga autoridad alguna sobre $y$ pese a ser su padre". Veamos primero la resistencia de Rodríguez a las explicaciones asociativistas de la autoridad paternal. Para Rodríguez ser padre es una cuestión esencialmente biológica. Obviamente, si esto es correcto el hecho de ser padre no puede fundar una autoridad especial. Conocemos demasiados padres biológicos que no sólo no tienen sino que no deberían tener autoridad sobre sus hijos. Pero la paternidad biológica es una concepción más que dudosa de la paternidad. Ser padre no es estar biológicamente vinculado sino, esencialmente, estar en una especial relación con alguien, más precisamente, la relación de paternidad. El hecho de que la paternidad no debe asociarse a una cuestión biológica es clara y es lo que nos permite afirmar que alguien es "padre" a pesar de no haber tenido intervención biológica en la creación de su hijo, si es capaz de crear la relación relevante, por ejemplo adoptándolo. Si la concepción de la paternidad que yo sugiero es correcta, si la paternidad es una cuestión no biológica sino relacional, no es difícil aceptar que uno de sus elementos constitutivos sea su autoridad y, por lo tanto, que no hay, o no puede haber, padres sin autoridad. De modo similar a lo anterior se puede explicar la resistencia de Rodríguez a aceptar las explicaciones asociativas de la autoridad del derecho y la fuente del error de su visión. Así como una concepción defectuosa de la paternidad lleva a Rodríguez a afirmar que ser padre no es una condición suficiente de autoridad sobre los hijos, una concepción defectuosa del derecho es lo que lleva a Rodríguez a afirmar que el derecho no tiene necesariamente autoridad sobre sus súbditos. 
las que usualmente prevalecen en países como el nuestro. Ambos creen que en estas circunstancias es imposible satisfacer las condiciones de membresía tal como ellos las conciben y, por lo tanto, que en ellas el derecho no puede pretender portar autoridad.

Seleme e Iglesias están muy cerca entre sí respecto de cómo concebir a la membresía. Seleme piensa que para que alguien sea miembro de una comunidad no tiene que ser imposible para él aceptar el sistema de toma de decisiones de dicha comunidad ${ }^{15}$ mientras que Iglesias considera que alguien es un miembro de la comunidad cuando ha fusionado su vida moral y política con la comunidad tratándose con los demás miembros en los términos impuestos por un esquema capaz de crear una base razonable para la cooperación social entre quienes merecen la misma consideración y respeto ${ }^{16}$.

No obstante las diferencias que parecen surgir de las descripciones precedentes, Seleme e Iglesias están de acuerdo en la sustancia pues ambos creen que en una comunidad liberal la membresía exige una distribución de recursos que sea capaz de garantizar a todos lo que Iglesias llama, siguiendo a Rawls, los "mínimos constitucionales", esto es, el ejercicio efectivo de los derechos civiles y políticos básicos. Sobre la base de estas ideas mis comentaristas afirman que el test de membresía que yo ofrezco es demasiado fácil de satisfacer ${ }^{17} \mathrm{y}$, por lo tanto, que mi visión de la autoridad del derecho es demasiado tolerante.

\footnotetext{
${ }^{15}$ Seleme considera que la "aceptabilidad" del sistema de toma de decisiones colectivas depende de la cultura política de aquellos a quienes dicho sistema pretende obligar. Yo estoy de acuerdo con ello pues a mi criterio la teoría de la membresía es "culturalmente" relativa.

${ }^{16}$ Iglesias, a diferencia de Dworkin, no condiciona la membresía a una comunidad política al hecho de que dicha comunidad exprese una igual preocupación por el bienestar de todos sus miembros. Iglesias es menos exigente ya que parece contentarse con que la comunidad pueda ser vista como una base razonable para la cooperación.

${ }^{17}$ Seleme también critica mi test de membresía por ser inconsistente con mi concepción de la comunidad pues, según dice, mi concepción de la comunidad es el producto de una conjunción de elementos procedimentales y sustantivos mientras que mi test de membresía es el producto de una disyunción de dichos elementos en tanto mi test determina que soy miembro de una
} 
En lo que sigue pretendo mostrar dos cosas. Primero, que es un error pensar, como lo hacen mis comentaristas, que mi concepción de la membresía sea demasiado fácil de satisfacer y, por lo tanto, que ella conceda al derecho autoridad con demasiada facilidad. En segundo lugar, quiero documentar que mi concepción de la membresía debe ser preferida a la de Seleme e Iglesias, no solo porque sirve mejor el valor del "cambio sistémico"18 -el valor de la

comunidad política cuando se satisfacen alternativamente un elemento sustantivo o uno procedimental (por ejemplo, o partícipes de hecho o beneficiarios de hecho de las decisiones colectivas.) En otras palabras, Seleme cree que dado mi concepción de la comunidad política yo debería concebir el test de membresía de un modo más exigente y considerar que alguien es miembro de la comunidad política sólo cuando es tanto de hecho beneficiario como de hecho partícipe de las decisiones comunes. Pero Seleme no tiene razón. Una comunidad política no es una conjunción de elementos procedimentales y sustantivos sino que es una conjunción de aspiraciones y convicciones procedimentales y sustantivas. (En LAD sostuve "una comunidad política...constituye, en esencia, una asociación que combina tanto proceso como sustancia. Una comunidad política es el resultado de la conjunción entre la aspiración de moldear en conjunto un destino común -lo que constituye un elemento procedimental- y la convicción de que en comunidad es más fácil proveer a la satisfacción de las necesidades o intereses individuales -facilidad que, a su vez, hace inteligible la aspiración de moldear en conjunto un destino comúnlo que constituye un elemento sustantivo"). Dado este carácter "aspiracional" la membresía no debe definirse en función de los elementos que constituyen una comunidad política perfecta sino que basta con aquellos elementos que garantizan que sea posible para una comunidad cambiar sistémicamente en la dirección de la realización de las aspiraciones que la definen. Mi test de membresía responde a esta idea. Mi test sólo requiere la satisfacción alternativa de elementos procedimentales o sustantivos porque basta con la satisfacción de hecho de alguno de estos elementos -es decir que la gente de hecho cuenta o de hecho participa en el proceso de toma de decisiones colectivas y siempre que no haya restricciones para participar o contarpara abrir la posibilidad de que la comunidad pueda evolucionar en la dirección de la concreción de las aspiraciones que la caracterizan.

${ }^{18}$ Grosman cree que dado lo que considero valioso -el cambio sistémico- debería encarar mi trabajo de un modo distinto. En lugar de centrar mis argumentos en las razones que un individuo puede tener para hacer aquello que es jurídicamente debido debería centrarme en los deberes del estado (o más bien en el derecho de un estado a imponer su autoridad sobre sus súbditos). Yo resisto la sugerencia de Grosman (Gabriel Bouzat quiso convencerme de lo mismo en muchas discusiones). Mi resistencia a adoptar la visión que sugiere Grosman no proviene de 
constitución de una comunidad entre aquellos sujetos a la misma autoridad y el valor de que ella cambie como tal, que según mi opinión sustenta una explicación asociativa de la autoridad del derecho- sino, además, porque sirve mejor el valor de la justicia.

Empezaré por recordar el test de membresía. En LAD sostuve que una persona no es miembro de una comunidad política cuando las instituciones de dicha comunidad: a) están organizadas precisamente a los efectos de que o sus opiniones o sus intereses no cuenten en el proceso de toma de decisión colectiva, o b) cuando su funcionamiento impida que como cuestión de hecho sus opiniones y sus intereses cuenten en dicho proceso.

Más allá de las dificultades interpretativas que puede presentar el test de membresía -no siempre es fácil saber cuáles son los propósitos y objetivos de una institución- ${ }^{19}$ lo que resulta claro es que este test determina que cuando las instituciones de una comunidad son causalmente responsables de que algunos sean marginados por otros del proceso político o de la distribución

que yo vea una simetría entre las razones individuales para obedecer el derecho y las razones del estado para imponerlo (Rodríguez correctamente rechaza la existencia de simetría) sino en razón de que lo que yo hago es más importante que lo que Grosman sugiere que yo debería hacer. Si sólo probásemos que el estado puede usar la coerción para imponer el derecho, pero no que nosotros debemos obedecer el derecho, no habríamos hecho mucho para construir autoridad pues no podríamos operar mucho sobre la conciencia ciudadana. En cambio si mostramos que tenemos razones para obedecer el derecho podremos operar sobre la conciencia ciudadana pues contaremos con una herramienta poderosa para censurar a quienes al desobedecer el derecho impiden o dificultan el cambio sistémico y para encomiar a quienes, obedeciéndolo, lo promueven.

${ }^{19}$ A veces ello dependerá de las circunstancias del caso, del contenido de las decisiones comunitarias, lo que a su vez dependerá de las intenciones individuales de quienes participan de dichas decisiones comunitarias. Algunos casos serán obvios, por ejemplo la decisión mayoritaria de alterar los circuitos electorales para que algunos grupos tengan más dificultades para imponer sus visiones (la práctica del "gerrymandering") y otros más difíciles, por ejemplo, la decisión de imponer un piso o número mínimo de votos en los sistemas proporcionales de voto para obtener un representante en la legislatura. 
de los beneficios del trabajo común, el derecho pierde autoridad respecto de $\operatorname{ellos}^{20}$ (y, en virtud de lo dicho en la sección precedente, deja de ser derecho para ellos) en tanto ellos no pueden ser considerados como miembros de la comunidad fuente de dicho derecho.

Ahora bien, del mismo modo que todo test de membresía a un club o a alguna otra organización social presupone la existencia de dicho club u organización social, el test de membresía que yo ofrecí, en tanto test de membresía a una comunidad política, presupone la existencia de una comunidad política ${ }^{21}$.

En LAD aclaré qué era lo que yo entendía por una "comunidad política" diferenciándome tanto de aquellos para quienes la comunidad política es únicamente el producto de aspiraciones o de gobierno colectivas como de aquellos para quienes es una herramienta para la realización de intereses individuales. A diferencia de ambos sostuve que una comunidad política es un conjunto de individuos que se relacionan entre sí con el propósito de conjugar la aspiración de moldear en conjunto un destino común -aspiración colectiva- con la aspiración de proveer mejor a las necesidades o intereses individuales -aspiración individual-. Ahora, a la luz de las críticas de mis comentaristas, veo lo que dije en LAD como relativamente incompleto. Me

\footnotetext{
${ }^{20} \mathrm{El}$ énfasis que mi test pone en los propósitos u objetivos de las instituciones es distinto al énfasis que pone en las consecuencias del funcionamiento de dichas instituciones en virtud de que basta para afectar la membresía de alguien a su comunidad que alguna institución haya sido diseñada con el propósito u objetivo de impedir su participación en el proceso político o su habilidad para contar al momento de la distribución de beneficios sociales mientras que las consecuencias o efectos solo cuentan si impiden ambas cosas a la vez.

${ }^{21}$ Seleme afirma que mi test de membresía es "individualista". El test de membresía debe ser "individualista" pues justamente define la pertenencia de un individuo a una entidad colectiva. Pero ello no implica que mis ideas sean también "individualistas". Muy por el contrario, mis ideas son bastante menos "individualistas" que las de Seleme en tanto pretenden mostrar que nuestras obligaciones no dependen de lo que decidamos sino de lo que decida una entidad colectiva a la que pertenecemos o de la cual somos miembros.
} 
faltó hacer referencia a un elemento definitorio de toda comunidad política -el poder- esto es, la aptitud de la comunidad política para determinar, por convicción o por coerción, la conducta de sus miembros. Ello fue bien advertido por Iglesias. Iglesias sostuvo que mi teoría dejaba demasiado “indefinido" el vínculo político pues yo no establecía con precisión quiénes eran aquellos que constituían el conjunto de los que tenían la obligación de obedecer el derecho. Por ello, Iglesias concluía, mi concepción de la autoridad del derecho no satisfacía adecuadamente el requisito de "particularidad" (el segundo requisito que según yo mismo debe satisfacer una teoría de la autoridad jurídica para ser aceptable). Iglesias escribió: “Si el único elemento que tomamos para calibrar qué es lo que me hace miembro de una comunidad política es que las instituciones no impidan por activa o por pasiva que mis intereses u opiniones cuenten en la toma de decisión pública, parece que cualquiera que no sea excluido pasará automáticamente a ser miembro de la comunidad".

El punto de Iglesias está bien tomado. Si de acuerdo con mi concepción de la membresía cualquiera que tuviera la posibilidad de contar en una decisión pública de una comunidad política fuera un miembro de dicha comunidad algo andaría mal con mi concepción de la "membresía” porque nunca diríamos que yo soy miembro de la comunidad política que constituyen los franceses aunque el sistema jurídico francés me conceda tanto el derecho de participar en sus elecciones como de expresar mis opiniones libremente en el suelo de Francia.

Este es el lugar para completar mi caracterización de la comunidad política y, con ello, mi concepción de la membresía. Para que exista una comunidad política hace falta que exista poder político, esto es, la posibilidad de determinar la conducta de los súbditos o, para poner la misma idea de un modo más familiar a los lectores de filosofía jurídica, un hábito general de sujeción a un proceso decisorio común. Este hecho es característico de las comunidades políticas. Por ello, no califican como una comunidad política la República Española en el exilio, en tanto no fue capaz de generar un hábito general de obediencia a sus pretendidas autoridades, ni un grupo de ciudadanos 
que quiera secesionarse de una entidad política preexistente pero que no han podido generar ninguna práctica social de acatamiento a normas dictadas en común. Más aun, la existencia de un hábito de sujeción a un proceso decisorio común es, además de constitutivo de una comunidad política, definitorio de su identidad al punto que no puede haber dos comunidades políticas cuando existe un solo hábito general de obediencia ${ }^{22}$. Esto creo que es fácil de aceptar y no constituye una alteración importante respecto de lo que antes ya había dicho.

Con esta aclaración en mente acerca de la necesidad de que exista poder o autoridad para que pueda hablarse de una comunidad política y, derivadamente, para que pueda hablarse de membresía a ella, volvamos a las críticas de mis comentaristas.

Mis comentaristas imaginan casos que, según ellos, muestran que mi test de la membresía es demasiado fácil de satisfacer y, por lo tanto, que yo veo obligaciones legales donde no debería haberlas. Como adelanté más arriba, quiero mostrar que ello no es así.

${ }^{22}$ El que no pueda haber dos comunidades cuando el hábito de obediencia se desarrolla respecto de la misma autoridad es lo que imposibilita que Iglesias defienda a Dworkin de mi crítica. He dicho en LAD que para Dworkin una comunidad puede sustentar la autoridad de su derecho cuando sus integrantes despliegan en sus vínculos un compromiso por, entre otras cosas, el igual bienestar de todos los demás. Yo critiqué a Dworkin usando el ejemplo de una comunidad política dividida donde conviven dos grupos religiosos muy diferentes y con recelo recíproco. Allí sostuve que Dworkin debería decir que los integrantes de cada grupo religioso no tienen la obligación de obedecer el derecho pues sus respectivas relaciones no expresan un igual interés por el bienestar de todos ellos, y agregué que ello no era aceptable porque, justamente, en la comunidad del ejemplo la obediencia a un derecho, dado que no existe otro catalizador social, es crucial para poder organizar la vida en común. Iglesias defiende a Dworkin de esta crítica y sostiene que, en realidad, en mi ejemplo habría dos comunidades y que el derecho como integridad regiría en cada una de ellas. Si lo que digo en el texto es correcto la defensa de Iglesias no puede ser efectiva porque la comunidad no es el colectivo de quienes se encuentran igualmente interesados por el bienestar de todos los demás sino el de aquellos que participan de un hábito general de obediencia a un proceso decisorio o autoridad común. Así, si la conducta de ambos grupos como cuestión de hecho es en general determinada por la autoridad común ellos no son dos comunidades sino una y la misma. 
Seleme nos invita a pensar en una comunidad en la que no hay restricciones normativas para participar o contar en el proceso colectivo de toma de decisiones y en la que, además, como cuestión de hecho, todos participan en dicho proceso. Seleme sostiene que si en dicha comunidad se decidiera mayoritariamente que la minoría debe ser sometida a la esclavitud yo debería concluir que los esclavizados tienen la obligación de obedecer esta decisión, sencillamente porque en los términos de mi test de membresía ellos son miembros de la comunidad que adoptó la decisión en cuestión. Seleme, con razón, cree que esta conclusión es inaceptable, lo que muestra que mi test de la membresía y la concepción de la autoridad del derecho que se apoya en dicho test son también inaceptables.

La esclavitud no es otra cosa que privar a quien se esclaviza de su calidad de fuente legítima de intereses y de opiniones para convertirlo en objeto de las opiniones e intereses de otros. Esclavizar a alguien es "cosificarlo", convertirlo en "cosa". Consiguientemente, la decisión de esclavizar a alguien, con independencia de que hubiere sido adoptada por mayoría y de que pudiere ser revertida en el futuro, debe ser vista como una decisión cuyo propósito u objetivo es que los intereses y las opiniones de algunos no cuenten en el proceso político y, como tal, como una manera de privar a quien se esclaviza de su estatus de miembro de la comunidad. Por ello, la decisión de esclavizar a alguien no puede ganar autoridad, por lo menos frente a aquel a quien se esclaviza.

El argumento anterior está articulado íntegramente con ideas que yo suscribo y que no contradicen en modo alguno el test de membresía que he ofrecido -el argumento rechaza la esclavitud precisamente en razón de que quien es esclavizado deja de ser miembro de la comunidad que pretende obligarlo- por lo que nadie puede pensar que el ejemplo de Seleme represente un problema para mí. Pero pensemos en otro ejemplo, diferente al de Seleme. Imagine un caso de esclavitud "económica". Piense que la mayoría decide expropiar, sin compensación, todos los bienes de algunos sin afectar (al menos normativamente) sus otros derechos civiles y políticos (o piense en el ejemplo 
que sugiere Grosman de normas jurídicas que no solo no combaten la injusticia distributiva sino que intencionalmente la profundizan.) Seleme e Iglesias sostendrían que después de que la expropiación se realice no se satisfarían los "mínimos constitucionales" -en esas circunstancias los expropiados tendrán menos de lo que necesitan para hacer uso efectivo de sus derechos y libertades básicos- $\mathrm{y}$, por lo tanto, el derecho no podría generar obligaciones. Afirmarían que yo, dado que en esta comunidad se satisface el test de membresía, estoy forzado a concluir lo contrario, independientemente de la injusticia resultante. Esto no es así. En virtud de que mi test afirma que alguien no es miembro de la comunidad política si las instituciones o las decisiones de dicha comunidad tienen como propósito u objetivo que sus intereses o sus opiniones no cuenten en el proceso de decisión, en todos aquellos casos en los que la medida que se hubiera de adoptar tuviera estos objetivos no habría obligación de obedecer las decisiones que pretenden ser autoritativas. Nadie puede decir que en el ejemplo las decisiones comunes no tienen por objetivo que los intereses de algunos no cuenten dado que, justamente, lo que se busca es perjudicar a los expropiados dejándolos sin propiedad. Pero, ¿qué sucedería si el propósito u objetivo de la decisión mayoritaria de expropiar no fuera, como se nos aparece a primara vista, perjudicar a los expropiados sino simplemente aprovecharse de sus bienes? En este caso, según mi visión, tampoco existiría ninguna obligación de obedecer. Recuerde lo que dije más arriba en el sentido de que el test de membresía presupone la existencia de una comunidad política, esto es, un conjunto de individuos que se relacionan conjugando la aspiración de moldear en conjunto un destino común con la aspiración de proveer mejor a las necesidades o intereses individuales y que desarrollan un hábito general de obediencia a una autoridad común. Dado este presupuesto del test de membresía podemos sostener que en casos de "esclavitud económica" el derecho no puede generar autoridad, independientemente de cuál hubiera sido el objetivo o propósito de la decisión de expropiar, en virtud de que la decisión de expropiar es un síntoma de que entre quienes expropian y quienes son expropiados ha dejado de existir una comunidad, esto es, una relación 
estructurada, en parte, alrededor de la aspiración de moldear un destino común para beneficios mutuos.

Lo anterior es todo lo que necesito decir para convencerlo de que mis comentaristas exageran cuando me imputan ver obligaciones legales donde no debería haberlas ${ }^{23}$. Si tenemos en cuenta que para que una comunidad política genere normatividad para su derecho y se constituya en una autoridad para sus súbditos es preciso que ella sea verdaderamente una comunidad política es posible sostener que el derecho no será autoritativo, aun cuando se satisfaga el test de membresía, en todos aquellos casos en los que las decisiones colectivas pueden ser vistas como síntomas de que la comunidad ha dejado de existir como tal porque ella ya no puede verse como el resultado de una conjugación entre la aspiración de moldear en conjunto un destino común con la aspiración de obtener beneficios mutuos.

V

En LAD sostuve que el valor del cambio sistémico -el valor de que se constituya una comunidad entre aquellos sujetos a la misma autoridad y que dicha comunidad cambie como tal- sustenta una explicación asociativa de la

\footnotetext{
${ }^{23}$ Seleme e Iglesias son partidarios de los mínimos constitucionales porque, no obstante su confesado "asociativismo" otorgan mucha relevancia normativa a lo que sucede después de que una decisión colectiva es adoptada. Así, piensan que si un procedimiento de toma de decisión colectiva no garantiza que tengamos lo suficiente para nuestra subsistencia, no puede generar normatividad. Esto es un error. La cantidad de recursos que nos otorga un procedimiento de toma de decisiones es irrelevante para determinar su legitimidad. De hecho, no dudaríamos en considerar legítimo y autoritativo un sistema de toma de decisiones colectivo que distribuyera los últimos alimentos de una comunidad sólo entre los más jóvenes (sea por su mayor aptitud para enfrentar las peripecias o por el hecho de que es un mal peor que vidas jóvenes se terminen o por cualquier otra razón). Si nosotros estuviéramos entre los más viejos en dicha comunidad deberíamos considerar autoritativo el hecho de que la comunidad decidió del modo en que lo hizo ( $\sin$ perjuicio de que dicha decisión no necesita ser una razón última para nosotros) lo que muestra que la cantidad de recursos que nos otorgue un procedimiento no define su normatividad.
} 
autoridad del derecho. Ahora bien, usted podría pensar que una concepción de la membresía más exigente que la mía, digamos, una que como la del mismo Seleme o la de Iglesias incluye la exigencia de los "mínimos constitucionales", también satisface este valor y que debería ser preferida sobre la mía pues, además, honra mejor el valor de la justicia distributiva. En LAD ya sugerí la respuesta a esta pretensión. Allí sostuve que concepciones de la membresía con más exigencias que la mía -me refería a la concepción de Dworkin que requiere un igual compromiso con el bienestar de todos para que pueda hablarse de membresía y de comunidad- son, en realidad, hostiles al valor del cambio sistémico, pues en las circunstancias en las que estas exigencias adicionales no son satisfechas el derecho pierde su autoridad privándonos de la única herramienta con la que contamos para organizar nuestra vida en común en sociedades plurales. Por ello, si usted valora el cambio sistémico, tal como yo lo hago, no debería proponer concepciones más exigentes que la mía, sean como las de Dworkin o como las de Seleme o Iglesias.

La idea de que si proponemos concepciones de la membresía más exigentes que incluyan la satisfacción de los mínimos constitucionales atentamos contra el cambio sistémico asume que un derecho autoritativo -un derecho con autoridad intrínseca- es la única manera de organizar una sociedad plural y que, por lo tanto, un derecho autoritativo es una precondición de que la comunidad sea capaz de organizarse como comunidad actuando de consuno. Si ello no fuera así, si el cambio sistémico fuera posible incluso cuando el derecho no fuera autoritativo, si la comunidad pudiera organizarse como tal recurriendo a otras fuentes de normatividad, una concepción de la membresía más exigente que la mía no enfrentaría el problema que señalo más arriba pues no podría ser sindicada como la causa de que no podemos organizarnos comunitariamente.

Seleme cree que es posible constituir una comunidad o realizar el cambio sistémico aún cuando el derecho no tenga autoridad pues es posible obedecer al derecho por razones estratégicas o instrumentales. Afirma que "pueden existir consideraciones estratégicas que muestren que el mejor modo de... 
(construir la "legitimidad" dice Seleme, construir la "comunidad" o "cambiar sistémicamente" diría yo)... sea sostener el presente esquema institucional y buscar internamente su reforma.. (esto es, obedecer el derecho)". Si Seleme tuviera razón, si pudiéramos recurrir a razones estratégicas para realizar el cambio sistémico ("construir la legitimidad" en términos de Seleme), los "mínimos constitucionales” no serían problemáticos. Más aun, si Seleme tuviera razón, si un derecho autoritativo no fuera necesario para actuar de consuno pues para ello bastará obedecer el derecho por razones estratégicas o instrumentales, su concepción de la membresía -o para el caso la de Iglesiasdeberían ser efectivamente preferidas dado que ellas tienen una clara ventaja expresiva pues impiden que una comunidad política se legitimice antes de haber resuelto las injusticias más inaceptables en la distribución de sus recursos.

¿Contamos con razones para someternos al derecho y para, de ese modo, actuar como comunidad en las circunstancias en las que el derecho no tiene autoridad? ¿Es posible construir la comunidad (o construir la legitimidad como diría Seleme), por razones “estratégicas o instrumentales”? ¿Es posible encontrar alguna fuente normativa por referencia a la cual podamos actuar de consuno en aquellos casos en los que el derecho no nos da razones intrínsecas para actuar?

Todos los autores que creen en la posibilidad de explicaciones instrumentales de la autoridad del derecho dan a estas preguntas respuestas afirmativas. Yo disiento. No creo que sea posible sustentar la obligación de obedecer el derecho basados en consideraciones estratégicas o instrumentales. Si sólo tuviéramos razones estratégicas o instrumentales -si debiéramos obedecer al derecho estratégica o instrumentalmente porque, digamos, ello contribuye a la justicia o a la satisfacción de los mínimos constitucionales- no nos sería posible explicar por qué tenemos que obedecer nuestro derecho aun cuando con nuestra obediencia a otro derecho -un derecho distinto al nuestro- podríamos realizar una mayor contribución a los valores respecto de los cuales la obediencia al derecho es una estrategia o un instrumento. Como dije en LAD, toda explicación instrumental de la obligatoriedad del 
derecho falla porque no puede dar cuenta de la "intimidad" normativa existente entre quien se encuentra obligado y $s u$ derecho, esto es, de que es nuestro derecho el que nos obliga no en razón de que obedeciéndolo contribuiremos a la realización de otros valores sino por el hecho de ser el derecho de nuestra comunidad $^{24}$.

Pero este no es el único problema de Seleme. La idea de que es posible organizarnos como comunidad (o construir la legitimidad) recurriendo a razones estratégicas o instrumentales tiene otros frentes. En efecto, cuando afirmamos que debemos obedecer el derecho por su autoridad intrínseca afirmamos una obligación incondicionada que, como tal, permite organizar nuestra vida en común también en circunstancias donde desconocemos qué harán los demás o donde el derecho no es una fuerza motivadora universal. En estas circunstancias es para nosotros posible obedecer porque el carácter incondicionado de la obligación nos permite exigir y esperar la obediencia de los demás ${ }^{25} \mathrm{y}$, por tanto, nos da herramientas para pensar que existen posibilidades de que se realice el valor que la obediencia generalizada al

\footnotetext{
${ }^{24}$ Usted podría atacar mi escepticismo. Podría replicar mis comentarios sosteniendo que nuestra sumisión al derecho argentino, por ejemplo, es la mejor manera de promover la justicia o los mínimos constitucionales en la Argentina y que es la promoción de este valor -la justicia o los mínimos constitucionales en la Argentina- lo que justifica instrumental o estratégicamente que obedezcamos al derecho. Esta réplica no es posible. No está disponible para alguien que cree que el derecho no es autoritativo incluso en circunstancias donde no se satisfacen la justicia o los “mínimos constitucionales". Ello es así en razón de que esta réplica presupone que nuestro deber de promover la justicia o los mínimos constitucionales ya está localizado en alguna comunidad política y la única manera que tenemos de defender esta localización es presuponer que existe alguna razón para que hagamos lo que es necesario para que nuestra comunidad política exista como tal independientemente de la satisfacción de la justicia y los mínimos constitucionales, justamente lo que afirma quien cree en la autoridad del derecho y lo que debe negar quien sostiene que el derecho no tiene autoridad en aquellas circunstancias en las que no se satisfacen la justicia ni los "mínimos constitucionales".

${ }^{25}$ Nos permite, como lo he puesto en otro lugar, "confiar en el derecho". Ver, Confianza en el Derecho, en La Confianza y el Derecho, Marcelo Bergman y Carlos F. Rosenkrantz (ed), Fondo Editorial de América Latina, México, en prensa (2006).
} 
derecho instancia. Ello no sucederá así si, como sugiere Seleme, las razones para obedecer el derecho fueran solo estratégicas o instrumentales. Efectivamente, en este caso mi obligación de obedecer el derecho dependerá de si lo que hacen los demás es lo necesario para realizar el valor que la obediencia generalizada al derecho instancia (el cambio sistémico o, en términos de Seleme, la legitimidad). El problema es que cuando mi obligación de obedecer el derecho depende de lo que hagan los demás, no tendré razones para obedecer el derecho en aquellas circunstancias en las que desconozco qué es lo que ellos hacen o harán y, lo que es más grave aún porque generará un círculo vicioso de desobediencia, no tendré razones para obedecer el derecho en aquellos casos en los que los demás de hecho no hacen lo que el derecho ordena. Más aún, en ambos tipos de casos, nadie tendrá razones para obedecer el derecho en tanto la obediencia de los demás depende de mi propia obediencia. En resumen, el problema de intentar fundar la obediencia al derecho en razones estratégicas o instrumentales es que estas razones no constituyen herramientas categóricas para organizarnos comunitariamente y ello, si creemos en el valor del cambio sistémico, es un problema fatal, porque sin herramientas categóricas no podemos actuar de consuno en aquellas circunstancias en las que no tenemos firmes garantías de que todos lo harán ${ }^{26}$.

VI

Si creemos en el valor del cambio sistémico, el valor de que una comunidad se constituya y cambie como comunidad, debemos resistir la pretensión de supeditar la autoridad del derecho a la satisfacción de mínimos constitucionales más allá de que respetando la autoridad del derecho debemos

\footnotetext{
${ }^{26}$ Obviamente, usted puede sostener que el cambio sistémico no es un bien pero esa no parece ser la posición de mis comentaristas, salvo la de Rodríguez. Si así fuera usted enfrentará, tal como le sucede a Ralws y a las concepciones epistémicas, la imposibilidad de explicar la razón por la que debemos obedecer nuestro derecho por oposición a un derecho más eficiente en la realización del bien respecto del cual de acuerdo con su concepción el derecho es un instrumento.
} 
hacer todo lo necesario para que dichos mínimos constitucionales sean satisfechos. Ello no debería sorprenderlo. En definitiva, los mínimos constitucionales no son una exigencia que provenga de la necesidad de organizarnos como comunidad. Su origen pareciera estar en el campo de la justicia. Veamos ahora si la adhesión al valor de la justicia debería convencernos de que es una buena idea condicionar la autoridad del derecho a los mínimos constitucionales.

Antes que nada quiero aclarar mi propia posición en este punto. En primer lugar, quiero destacar que mi posición acerca de la autoridad del derecho no me impide afirmar con vehemencia que dentro del derecho debemos hacer todo lo que está a nuestro alcance para realizar la justicia distributiva, para que todos tengan la cantidad de recursos que corresponden en virtud de nuestra común pertenencia a una misma comunidad política. En LAD afirmé que el derecho es autoritativo incluso en situaciones de injusticia distributiva. Esta conclusión implica que en ciertas circunstancias la realización de la justicia distributiva no será operativa porque no podrá determinar la forma en que debemos actuar. Sin embargo, esta conclusión no debe hacernos pensar que el derecho conservaría su autoridad si el derecho (siempre, usual o necesariamente) hiciera imposible una distribución de recursos moralmente aceptable. Si el derecho, por su propia naturaleza o estructura, estuviera destinado a consagrar o reproducir la injusticia distributiva -si el derecho fuera un mecanismo de protección de privilegios o de opresión- Grosman tendría razón y sería insensato insistir que el derecho tiene autoridad o que debemos obedecerlo como sería insensato sostener cualquier valor que (siempre, usual o necesariamente) impida la realización de otro valor. Por ello, incluso para mí que creo que el punto del derecho no es necesariamente la realización de la justicia distributiva, es importante investigar las relaciones de posibilidad entre el derecho y la manera en que los recursos de una sociedad se distribuyen entre sus miembros.

Para empezar quiero enfatizar que mi impresión es que las comunidades que satisfacen el test de membresía que yo he propuesto generan una dinámica que hace más probable la realización de la justicia. Así, cuando no hay 
impedimentos normativos que silencien nuestra opinión o que impidan que nuestros intereses cuenten en el proceso de adopción de decisiones comunes y existen garantías de que nuestra opinión o nuestros intereses de hecho contarán en dicho proceso -las condiciones necesarias para que de acuerdo con el test de membresía alguien sea considerado parte de una comunidad y, por lo tanto, obligado por su derecho- se ventilarán distintas visiones acerca de la manera en que se deben distribuir los recursos sociales y se crearán incentivos para que éstos se distribuyan de un modo más aceptable para todos, dado que en este tipo de comunidades la mejor manera (y quizás la única) de conseguir un beneficio distributivo perdurable para uno es ofrecer iguales o similares beneficios para todos los demás. Creo que esto es fácil de percibir, forma parte del saber común y una de las razones por las que las sociedades con democracia política son usualmente más justas distributivamente hablando.

Obviamente, los incentivos para distribuir equitativamente los beneficios de la cooperación social serán siempre imperfectos. Aún cuando no existan obstáculos normativos para participar y contar y aún cuando todos tengan garantizado que contarán o participarán en el proceso de toma de decisiones, siempre será posible que grupos cohesionados y consolidados se apropien inequitativamente (aunque no exclusivamente) de los beneficios de la cooperación social dificultando la formación de coaliciones cuyo objetivo sea mejorar el perfil de la distribución de los recursos económicos y sociales (la cita de Borges de que la democracia es un abuso de la estadística viene al caso aquí). La posibilidad de que esto suceda no se puede despreciar, como lo testimonian sociedades con democracia política pero severamente injustas que conocemos.

De todos modos, esta limitación no nos debe hacer pensar que los mínimos constitucionales condicionan la autoridad del derecho. En primer lugar, la experiencia nos muestra que la justicia no puede instanciarse en contextos donde el derecho no tiene autoridad. No conocemos ninguna comunidad que haya sido justa -que haya distribuido los recursos sociales de un modo que satisfaga criterios de justicia- antes de ser capaz de regularse 
como tal. El derecho es un precursor necesario, aunque obviamente no suficiente, de la justicia distributiva. Si esto es correcto y si una comunidad sólo puede transitar hacia la justicia distributiva ya equipada con la capacidad de dotar de autoridad a su derecho, los mínimos constitucionales no pueden ser funcionales a la justicia distributiva precisamente porque en ciertas circunstancias los mínimos constitucionales privan al derecho de autoridad, impidiendo de ese modo que se realicen las precondiciones que deben satisfacerse para posibilitar una distribución justa.

Pero existe otra razón menos vinculada a cuestiones fácticas, pero más poderosa creo yo, para resistir la inclusión de los mínimos constitucionales en nuestra concepción de la membresía. Lo que está detrás de la idea de los mínimos constitucionales es que parece inapropiado pedirle a usted que se someta al derecho de su comunidad si ella no ha hecho lo suficiente por usted, esto es, si ella no le ha garantizado la cantidad de recursos que usted necesita para ejercer dignamente sus derechos constitucionales. Ahora bien, la excepción que introducen los mínimos constitucionales en su favor, al liberarlo de la obligación de obedecer el derecho en aquellas circunstancias donde usted tiene menos recursos de los que debería tener, no es gratis. El precio de su liberación es alto porque cuando usted es liberado de obedecer al derecho queda inhabilitado para invocar un argumento poderoso para que su comunidad se ocupe de usted.

Déjenme explicar este punto. La razón por la que usted tiene una mayor legitimidad para reclamar justicia en su comunidad-mayor por ejemplo de la que tiene un extranjero que no vive en ella aún cuando esté más necesitado que usted o sea mucho más pobre- es el hecho de que usted es un miembro de la comunidad ${ }^{27}$. Su comunidad se debe ocupar prioritariamente de usted

\footnotetext{
${ }^{27}$ Grosman dice en su comentario que "el punto de contacto relevante entre el individuo y las normas jurídicas son sus actos, no su status dentro de la comunidad”. Esto es un error. Yo no estoy obligado a obedecer el derecho de su país qua derecho por el hecho de que mis actos tengan allí consecuencias. No debo ir a la guerra aunque el derecho de su país me obliga a hacerlo, por ejemplo, por haberle exportado mercaderías a usted. Sólo debo obedecerlo si soy un miembro con usted de su comunidad política.
} 
por reciprocidad con el hecho de que su comunidad puede obligarlo a usted a hacer lo que ella le ordena. Como lo ha dicho T. Nagel tenemos derecho a un trato especial por parte de nuestra comunidad porque nuestra comunidad toma decisiones en nuestro nombre y nos hace responsables por ellas ${ }^{28}$. Ahora bien, si por cualquier razón usted dejara de estar obligado a hacer lo que su comunidad le ordena usted perdería su derecho a un trato especial y, por lo tanto, se debilitaría su pretensión de que su comunidad se ocupe de usted antes que de ningún otro. Obviamente, esto no implica que su comunidad se pueda desentender absolutamente de su suerte cuando usted no hace aquello que constituye la contrapartida de su derecho a un trato especial, pero sí que usted, para reclamar a su comunidad por su situación, deberá articular su reclamo recurriendo a algún argumento distinto a la reciprocidad que su comunidad le debe, que no siempre estará a su disposición, como por ejemplo, que ha sido perjudicado por su comunidad o que está peor que todos aquellos que, independientemente de no ser miembros de la comunidad, están mal, etc ${ }^{29}$.

\footnotetext{
${ }^{28}$ Nagel recientemente ha defendido esta idea. Así, en The Problem of Global Justice, ha afirmado que la razón por la que estamos especialmente habilitados para reclamar a nuestra comunidad es que "the community makes us responsible for its acts, which are taken in our name". Ver Nagel, Tomas, The Problem of Global Justice, Philosophy and Public Affairs, vol. 33 n. 2, pag. 129.

${ }^{29}$ Me parece que lo que digo en el texto está de algún modo relacionado con una idea curiosa de Seleme. Seleme sostiene que "cuando un individuo está alienado todos lo están”. Bajo alguna interpretación esta formulación es equivocada. Así, por ejemplo, no puede ser verdad que la alienación de Juan libera a Pedro y a Martín, que no están alienados en modo alguno, de obedecer el derecho de la comunidad de la que Pedro y Martín son miembros. Pero bajo otra interpretación la idea de Seleme es similar a la que desarrollo en el texto. Seleme puede estar queriendo decir, simplemente, que si Juan está alienado de la comunidad de la que son miembros Pedro y Martín, estos también están alienados respecto de aquél o, puesto en otras palabras, que nadie puede tener las obligaciones de un miembro de una comunidad frente a otro que, a su vez, no tiene dichas obligaciones frente a él. Si ésta es la interpretación correcta de lo que quiere decir Seleme, su posición implica la mía porque él debería decir, como yo lo hago, que al liberarme de la obligación de obedecer su derecho, los mínimos constitucionales me inhiben de
} 
En conclusión, si los mínimos constitucionales nos liberaran de la obligación de obedecer el derecho cuando somos víctimas de la injusticia distributiva, también nos quitarían el mejor argumento que podemos invocar para que los demás miembros de la comunidad a la que pertenecemos se ocupen prioritariamente de nuestro bienestar. Esto es, si nos importan los que sufren las consecuencias de la injusticia distributiva, es un problema y sumado al hecho de que existe una prioridad de realización entre la obediencia al derecho y la justicia distributiva nos debe llevar a concluir que debemos resistir la propuesta de incorporar la satisfacción de los mínimos constitucionales como uno de los elementos de la membresía y, por lo tanto, como uno de los requisitos que el derecho debe satisfacer para ser autoritativo.

\section{VII}

Rodríguez no lo dice expresamente pero su idea de que el derecho no puede determinar per se la manera en que debemos comportarnos en contextos de desigualdad económica, en última instancia, se sustenta en una idea mucho más general que él también suscribe y que matiza toda su contribución, más precisamente, que la justicia distributiva ("la igualdad" dice Rodríguez) es la

reclamarle a usted que se ocupe prioritariamente de mí.

En otro orden de cosas, Grosman sostiene que la "obligación moral de obedecer el derecho" no puede depender únicamente de cómo el derecho me trata a mí. Ella debe depender, también, de cómo el derecho trata a las otras personas cuyos intereses se ven afectados por mi cumplimiento o incumplimiento de sus normas". Si lo que Grosman quiere decir es que en el balance de todas las razones que se pueden aplicar a mí al momento de decidir qué es lo que debo hacer, el impacto de lo que hago en los demás será siempre una consideración relevante, nada hay que objetar. Pero si Grosman quiere decir algo distinto, esto es, que no puedo saber si tengo una razón para hacer lo que el derecho ordena a menos que sepa cómo el derecho impacta en los demás y, además, que no puedo tener una razón si todas las cosas consideradas el derecho impacta (de un modo irrazonable) negativamente en los demás, Grosman está equivocado. Yo tengo una razón para hacer lo que el derecho ordena cuando soy un miembro de la comunidad que se expresa mediante dicho derecho. 
única y suprema virtud y que, como tal, es quien debe determinar, directa o indirectamente, todo lo que en todas las circunstancias cada uno de nosotros debe hacer.

Ahora bien, los hechos que nos caracterizan políticamente, el último tribunal de la verdad, corrección o plausibilidad en filosofía política y, por lo tanto, el lugar al que debemos recurrir para adjudicar nuestras discusiones filosóficas, militan en contra de las ideas de Rodríguez.

Nosotros nos caracterizamos por dispensarnos y aceptar un trato qua miembros de la comunidad política a la que pertenecemos -un trato que hace y justifica diferencias en la concesión de derechos y en la imposición de obligaciones por el hecho de que algunos son miembros con nosotros de la comunidad constituida por la sujeción a una autoridad común mientras otros no lo son- y este trato no sólo problematiza la convicción de que la justicia distributiva es lo único que vale-si la justicia distributiva fuera la fuente de toda normatividad no podríamos considerar relevante para la concesión de derechos y para la imposición de obligaciones la pertenencia a la comunidad política- sino que, además, muestra que la existencia y la continuidad de la comunidad política -el cambio sistémico- es un valor.

Si esto es correcto, si los hechos que nos caracterizan políticamente son inconsistentes con la idea de que la justicia distributiva es la única virtud, la resistencia de Rodríguez a reconocer la autoridad del derecho debería perder todo su atractivo pues dicha resistencia, tal como lo adelanté más arriba, depende críticamente de que la justicia distributiva reine sola en el universo de la normatividad.

Obviamente, Rodríguez podría defender su visión de los problemas que he discutido en LAD y de las tesis que allí he ofrecido señalando que el ideal de la justicia distributiva debe regularnos y, si los hechos que nos caracterizan políticamente son inconsistentes con ella, peor para estos hechos. Pero si Rodríguez se moviese en esta dirección ignorando lo que nos constituye políticamente, su visión terminaría siendo utópica en el mal sentido pues sería una visión para gente distinta a lo que nosotros somos o la que podemos llegar a ser después de la debida reflexión. 